\title{
Predictive value of body mass index to metabolic syndrome risk factors in Syrian adolescents
}

\author{
Mahfouz Al-Bachir ${ }^{1 *}$ and Mohamad Adel Bakir ${ }^{2}$
}

\begin{abstract}
Background: Obesity has become a serious epidemic health problem in both developing and developed countries. There is much evidence that obesity among adolescents contributed significantly to the development of type 2 diabetes and coronary heart disease in adulthood. Very limited information exists on the prevalence of overweight, obesity, and associated metabolic risk factors among Syrian adolescents. Therefore, the purpose of this study was to determine the relationship between obesity determined by body mass index and the major metabolic risk factors among Syrian adolescents.
\end{abstract}

Methods: A cross-sectional study of a randomly selected sample of 2064 apparently healthy Syrian adolescents aged 18 to 19 years from Damascus city, in Syria, was performed. Body mass index and blood pressure were measured. Serum concentrations of glucose, triglycerides, total cholesterol, high-density lipoprotein-cholesterol, and low-density lipoprotein-cholesterol were determined. Metabolic syndrome was defined using the national criteria for each determined metabolic risk factor. Individuals with a body mass index 25 to 29.9 were classified as overweight, whereas individuals with a body mass index $\geq 30$ were classified as obese.

A receiver operating characteristics curve was drawn to determine appropriate cut-off points of the body mass index for defining overweight and obesity, and to indicate the performance of body mass index as a predictor of risk factors.

Results: The obtained data showed that blood pressure and the overall mean concentrations of fasting blood sugar, triglycerides, cholesterol, low-density lipoprotein-cholesterol, and triglycerides/high-density lipoproteincholesterol were significantly higher in overweight and obese adolescent groups $(p<0.0001)$ in comparison with the normal group. Based on receiver operating characteristics calculation for body mass index and some metabolic risks, the data suggest the best body mass index cut-offs ranged between 23.25 and $24.35 \mathrm{~kg} / \mathrm{m}^{2}$.

Conclusions: A strong association between overweight and obesity as determined by body mass index and high concentrations of metabolic syndrome components has been demonstrated. Although body mass index values were lower than the international cut-offs, these values were good predictors of some metabolic abnormalities in Syrian adolescents; body mass index is a good predictor of these abnormalities in this population.

Keywords: Syrian adolescents, Body mass index (BMI), Blood pressure, Metabolic syndrome, Risk factors

\footnotetext{
* Correspondence: ascientific9@aec.org.sy

'Department of Radiation Technology, Atomic Energy Commission of Syria,

P.O. Box 6091, Damascus, Syrian Arab Republic

Full list of author information is available at the end of the article
} 


\section{Background}

According to the estimates of the World Health Organization (WHO), obesity has become a serious epidemic health problem in many parts of the world, estimated to be the fifth leading cause of mortality at a global level, causing approximately 2.8 million deaths per year [1]. As a result, it was estimated that of the projected 64 million deaths worldwide in 2015, 41 million (64\%) will result from chronic disease unless urgent action is taken [2]. Obesity is one of the main components of the metabolic syndrome (MetS), which is a cluster of risk factors for cardiovascular disease (CVD) [3]. These factors not only lead to reduced quality of life given their protracted nature, they also lead to premature death [4].

The risk of diseases related to this syndrome appears to increase as a function of the body fat percentage. For the purpose of risk stratification, it is convenient to have cutoff values of body fat content based on its observed association with disease $[5,6]$. A fat mass index was used in screening for the presence of MetS [3]. The American Health Association and other professional societies recommend assessment of obesity using indices such as body mass index (BMI) [7, 8].

Studies have indicated an increase in mortality of various causes with increased BMI, especially death from CVD in men [9]. Increased BMI was most prominently associated with body pain [10]. Overweight and obese young people are viewed by many public health and health care practitioners as needing attention because of the continued focus on biomedical constructions of appropriate body size and its relationship to "good health." Acceptance of the views that "thin is good" and "fat is bad" is considered paramount for successful public health control [11].

Taking all these issues into consideration, very limited information exists on the prevalence of overweight, obesity, and associated metabolic risk factors among Syrian adolescents. Therefore, the purpose of this study was to determine the relationship between obesity as determined by BMI and the major metabolic risk factors among Syrian adolescents.

\section{Methods}

\section{Participants}

A cross-sectional study consisting of a sample of 2064 healthy young men aged 18 to 19 years from Damascus city, in Syria, was performed. All participants underwent a clinical examination by physicians to exclude those with a clinical history of chronic diseases including cardiovascular, renal, and hepatic or any abnormalities that might affect body composition. Participants were asked to abstain completely from consuming food and drink in the 12 hours before visiting the testing field. All anthropometry measurements and sampling were completed during a single visit to the testing area. The study protocol was approved by the scientific research and the ethical committee of the Atomic Energy Commission of Syria (AECS). Each participant provided informed consent prior to participation after a detailed explanation of the study protocol. This study was performed in accordance with guidelines prescribed by the Declaration of Helsinki as developed by the World Medical Association.

\section{Anthropometry}

Body weight was measured using calibrated electronic scales (Seca, Model 7671321004; Germany; D = 0.05 to $0.1 \mathrm{~kg})$. The accuracy of the scales was confirmed by using weight of known mass $(20 \mathrm{~kg})$. Height was measured to the nearest $0.5 \mathrm{~cm}$ with a wall-mounted stadiometer (Seca, Model 225 1721009; Germany). Participants were measured in light underwear. BMI was identified as weight divided by height squared $\left(\mathrm{kg} / \mathrm{m}^{2}\right)$.

\section{Biochemical and clinical tests}

The main MetS risk factors and some clinically important parameters were included in this study. Systolic blood pressure (SBP) and diastolic blood pressure (DBP) were measured in adolescents in a sitting position after rest using a mercury sphygmomanometer. Blood samples were collected from all participating adolescents after 12 hours of overnight fasting. Serum was separated by centrifugation. Serum glucose (GOD-PAP method, Human Co.), cholesterol (Chol), low-density lipoprotein Chol (LDLChol), high-density lipoprotein Chol (HDL-Chol; CHODPAP method, Human Co.), triglycerides (TG; GPO-PAP method, Human Co.), and fasting blood sugar (FBS) were determined using commercial kits [12].

\section{Biochemical, clinical, and overweight/obesity cut-off values}

The normal range for each studied metabolic component was defined as follows: SBP (90 to $135 \mathrm{mmHg}$ ); DBP (60 to $89 \mathrm{mmHg}$ ); FBS (65 to $110 \mathrm{mg} / \mathrm{dl}$ ); TG (25 to $200 \mathrm{mg} / \mathrm{dl}$ ); Chol (50 to $200 \mathrm{mg} / \mathrm{dl}$ ); HDL-Chol (40 to $75 \mathrm{mg} / \mathrm{dl}$ ); LDL-CDL-Chol (less than $155 \mathrm{mg} / \mathrm{dl}$ ) [12]. Overweight and obesity were defined as a participant with BMI of 25 to $29.9 \mathrm{~kg} / \mathrm{m}^{2}$ and $\geq 30 \mathrm{~kg} / \mathrm{m}^{2}$, respectively according to the cut-off point recommended by WHO [13]. The normal value for TG/HDL-Chol is less than $3[14]$.

\section{Statistical analysis}

Statistical analyses were performed using the Statistical Package for the Social Sciences (SPSS) for windows (Version 17.0.1, 2001, SPSS Inc., Chicago, USA). Continuous variables were expressed as mean \pm standard deviation (SD), whereas categorical variables were represented by frequency and percentage. A receiver operating characteristics 
(ROC) curve was drawn to determine appropriate cut-off points of the BMI for defining overweight and obesity. The area under curve (AUC) with 95\% confidence interval (CI) values provided an indication of the performance of BMI as a predictor of health risk $[8,15]$.

\section{Results}

The mean values (mean $\pm \mathrm{SD}$, maximum and minimum) of the MetS components of the 2064 participants and the range of the BMI are illustrated in Table 1. As shown in Table 1, mean serum concentrations of glucose, TG, total Chol, LDL-Chol, TG/HDL-Chol and HDL-Chol were within the normal limits. These values were as follows: BMI $\left(23.14 \mathrm{~kg} / \mathrm{m}^{2}\right)$, SBP $(123.43 \mathrm{mmHg})$, DBP (74.40 mmHg), FBS $(89.49 \mathrm{mg} / 100 \mathrm{ml})$, TG $(91.84 \mathrm{mg} /$ $100 \mathrm{ml})$, total Chol $(136.36 \mathrm{mg} / 100 \mathrm{ml})$, HDL-Chol $(57.11 \mathrm{mg} / 100 \mathrm{ml})$, LDL-Chol $(62.04 \mathrm{mg} / 100 \mathrm{ml})$, and TG/HDL-Chol (1.61).

Of the 2064 participants, the following had values within the normal range: $1670(81 \%)$ had SBP (90 to $135 \mathrm{mmHg}), 1440(70 \%)$ had DBP (60 to $89 \mathrm{mmHg}$ ), 2039 (99\%) had FBS (65 to $110 \mathrm{mg} / \mathrm{dl}), 1981(96 \%)$ had Chol (50 to $200 \mathrm{mg} / \mathrm{dl}$ ), 1989 (96\%) had TG (25 to $200 \mathrm{mg} / \mathrm{dl}$ ), 2034 (99\%) had HDL-Chol (40 to $75 \mathrm{mg} / \mathrm{dl}$ ), 2064 (100\%) had LDL-Chol (less than $155 \mathrm{mg} / \mathrm{dl}$ ), 1950 (95\%) had TG/HDL-Chol (less than 3). These results are shown in Table 2.

Blood pressure and biomedical markers values increased significantly $(p<0.05)$ with increasing BMI value. Regarding the measurements of $\mathrm{BMI}$, the obese group (BMI $>30 \mathrm{~kg} / \mathrm{m}^{2}$ ) had higher values of SBP (127.3 $\mathrm{mmHg})$, DBP $(77.7 \mathrm{mmHg})$, FBS $(91.6 \mathrm{mg} /$ $100 \mathrm{ml})$, TG $(125.1 \mathrm{mg} / 100 \mathrm{ml})$, Chol $(153.6 \mathrm{mg} /$ $100 \mathrm{ml})$, LDL-Chol $(71.9 \mathrm{mg} / 100 \mathrm{ml})$, and TG/HDLChol (2.22) compared to participants who were not obese $\left(20<\right.$ BMI $\left.<25 \mathrm{~kg} / \mathrm{m}^{2}\right)$. However, no significant differences were observed for HDL-Chol between the analyzed groups (Table 3 ).
ROC curve analysis of the BMI was performed for blood pressure (SBP and DBP) and other lipid biomarkers like FBS, TG, Chol, HDL-Chol, LDL-Chol, and TG/HDL-Chol (Table 4). Area under the ROC curve was the highest for LDL-Chol (0.69\%). The BMI cut-off point for LDL-Chol for optimal sensitivity and specificity was $\left(24.35 \mathrm{~kg} / \mathrm{m}^{2}\right)$ with sensitivity at $60 \%$ and specificity at $72 \%$. Comparable ROC curves of other biomarkers were obtained: DBP (AUC 0.59 of optimal cut-off point $23.45 \mathrm{~kg} / \mathrm{m}^{2}$ ), TG (AUC 0.67 of optimal cut-off point $23.25 \mathrm{~kg} / \mathrm{m}^{2}$ ), Chol (AUC 0.67 of optimal cut-off point $23.75 \mathrm{~kg} / \mathrm{m}^{2}$ ), and TG/ HDL-Chol (AUC 0.66 of optimal cut-off point $23.45 \mathrm{~kg} /$ $\mathrm{m}^{2}$ ). AUC ranged between 0.44 and 0.81 and was statically significant for DBP, TG, Chol, LDL-Chol, and TG/HDLChol (Table 4).

\section{Discussion}

The prevalence of overweight and obesity is increasing rapidly in young populations worldwide, especially in developing countries. Childhood obesity is a major health issue. According to the International Obesity Task Force (IOTF), at least 500 million school children aged 5 to 17 years are overweight or obese. Many studies have reported an association between childhood obesity and the development of a cluster of cardiometabolic disease risk factors [16-19]. This cluster, which has been termed MetS, is associated with the development of diabetes and CVD in both childhood and adulthood; CVD is the leading cause of morality worldwide. In addition, MetS was associated with arterial stiffness, which was a cardiovascular outcome of MetS $[3,20]$. Results reported recently indicated that the percentage of individuals who presented MetS risk factors almost doubled over a 10-year period [21]. Therefore, it is very important to develop an effective screening tool of MetS and its individual components, and analyze their association with overweight and obesity. To the best of our knowledge, this is the first study addressing

Table 1 Baseline characteristics of body mass index and biochemical variables in Syrian adolescents (18 to 19 years)

\begin{tabular}{llcrr}
\hline Characteristics & $n$ & (Mean \pm SD) & Minimum & Maximum \\
\hline Body mass index $\left(\mathrm{kg} / \mathrm{m}^{2}\right)$ & 2064 & $23.14 \pm 3.94$ & 16.10 & 42.90 \\
Systolic blood pressure $(\mathrm{mmHg})$ & 2064 & $123.43 \pm 14.55$ & 90.00 & 180.00 \\
Diastolic blood pressure $(\mathrm{mmHg})$ & 2064 & $74.40 \pm 10.72$ & 45.00 & 105.00 \\
Fasting blood sugar $(\mathrm{mg} / 100 \mathrm{ml})$ & 2064 & $89.49 \pm 8.53$ & 65.00 & 12.90 \\
Triglycerides $(\mathrm{mg} / 100 \mathrm{ml})$ & 2064 & $91.84 \pm 44.06$ & 17.00 & 37.00 \\
Total cholesterol $(\mathrm{mg} / 100 \mathrm{ml})$ & 2064 & $136.36 \pm 33.04$ & 1.00 & 370.00 \\
High-density lipoprotein cholesterol $(\mathrm{mg} / 100 \mathrm{ml})$ & 2064 & $57.11 \pm 5.63$ & 0.18 & 30.00 \\
Low-density lipoprotein cholesterol $(\mathrm{mg} / 100 \mathrm{ml})$ & 2064 & $1.61 \pm 0.78$ & 31.00 & 195.00 \\
Triglyceride to high-density lipoprotein cholesterol & 2064.29 .34 & $14.63 \pm 0.92$ & 16.00 \\
Hematocrit (\%) & 2064 & 2064 & 56.00 \\
Hemoglobin $(\mathrm{mg} / 100 \mathrm{ml})$ & & 17.90 \\
\hline
\end{tabular}


Table 2 Classification of blood pressure and metabolic characteristics in Syrian adolescents (18 to 19 years)

\begin{tabular}{|c|c|c|c|c|}
\hline Characteristics & & Range & $n$ & $\%$ \\
\hline \multirow[t]{3}{*}{$\mathrm{SBP}(\mathrm{mmHg})$} & Lower & $<90 \mathrm{mmHg}$ & 13 & 0.6 \\
\hline & Normal & $90-135 \mathrm{mmHg}$ & 1670 & 80.9 \\
\hline & Upper & $>135 \mathrm{mmHg}$ & 381 & 18.5 \\
\hline \multirow[t]{3}{*}{$\mathrm{DBP}(\mathrm{mmHg})$} & Lower & $<60 \mathrm{mmHg}$ & 362 & 17.5 \\
\hline & Normal & 60-89 mmHg & 1440 & 69.8 \\
\hline & Upper & $>89 \mathrm{mmHg}$ & 262 & 12.7 \\
\hline \multirow[t]{3}{*}{ FBS (mg/100 ml)) } & Lower & $<65 \mathrm{mg} / 100 \mathrm{ml}$ & 1 & 0.0 \\
\hline & Normal & $65-110 \mathrm{mg} / 100 \mathrm{ml}$ & 2039 & 98.8 \\
\hline & Upper & $>110 \mathrm{mg} / 100 \mathrm{ml}$ & 24 & 1.2 \\
\hline \multirow[t]{3}{*}{ Chol (mg/100 ml) } & Lower & $<50 \mathrm{mg} / 100 \mathrm{ml}$ & 8 & 0.4 \\
\hline & Normal & $50-200 \mathrm{mg} / 100 \mathrm{ml}$ & 1981 & 96.0 \\
\hline & Upper & $>200 \mathrm{mg} / 100 \mathrm{ml}$ & 75 & 3.6 \\
\hline \multirow[t]{3}{*}{ TG (mg/100 ml) } & Lower & $<25 \mathrm{mg} / 100 \mathrm{ml}$ & 17 & 0.8 \\
\hline & Normal & $25-200 \mathrm{mg} / 100 \mathrm{ml}$ & 1989 & 96.4 \\
\hline & Upper & $>200 \mathrm{mg} / 100 \mathrm{ml}$ & 58 & 2.8 \\
\hline \multirow[t]{3}{*}{ HDL-Chol (mg/100 ml) } & Lower & $<40 \mathrm{mg} / 100 \mathrm{ml}$ & 20 & 1.0 \\
\hline & Normal & $40-75 \mathrm{mg} / 100 \mathrm{ml}$ & 2034 & 98.5 \\
\hline & Upper & $>75 \mathrm{mg} / 100 \mathrm{ml}$ & 10 & 0.5 \\
\hline \multirow[t]{2}{*}{ LDL-Chol (mg/100 ml) } & Lower & $<155 \mathrm{mg} / 100 \mathrm{ml}$ & 2064 & 100 \\
\hline & Upper & $>155 \mathrm{mg} / 100 \mathrm{ml}$ & 0 & 0.0 \\
\hline \multirow[t]{2}{*}{ TG/HDL-Chol } & Lower & $<3 \mathrm{mg} / 100 \mathrm{ml}$ & 1950 & 94.5 \\
\hline & Upper & $>3 \mathrm{mg} / 100 \mathrm{ml}$ & 114 & 5.5 \\
\hline
\end{tabular}

$S B P$ systolic blood pressure, $D B P$ diastolic blood pressure, $F B S$ fasting blood sugar, TG triglycerides, Chol cholesterol, HDL-Chol high-density lipoprotein cholesterol, LDL-Chol low-density lipoprotein cholesterol, TG/HDL-Chol triglycerides/ high-density lipoprotein cholesterol

the association of BMI and the components of MetS among Syrian adolescents aged 18 to 19 years.

In this study, a strong association between obesity as defined by $\mathrm{BMI}$ and the risk of higher concentrations of blood pressure, FBS, total Chol, TG, HDL-Chol, and TG/HDL in Syrian adolescents has been demonstrated.
These findings demonstrate the risk of obesity at these early ages, with changes in the MetS components. Among the metabolic components, mean SBP $(123.4 \pm 14.55)$ was elevated in $19 \%$ of the whole group. Also, mean DBP ( $74.4 \pm 10.72)$ was elevated in $12.7 \%$. Increased FBS, TG, Chol, and TG/HDL were present in $1.2 \%, 2.8 \%, 3.6 \%$, and $5.5 \%$ of those investigated. Their blood pressure, both systolic and diastolic, was the most prevalent of the metabolic risk factors, followed by total Chol and TG. There was a significant increase in blood pressure in the overweight group as compared to the normal group and a significant increase in blood pressure in the obese adolescent group compared to the overweight group $(p<0.0001)$. Similar trends were observed for FBS, TG, total Chol, LDL-Chol, and TG/HDL-Chol. We also observed that the metabolic abnormalities were more significant and frequent in individuals with higher BMI values, especially in obese adolescents compared to those considered to have normal weight or overweight. Obese adolescents had higher abdominal fat, which is associated with cardiometabolic alterations such as LDL-Chol, increased triglycerides and LDL-Chol, and increased blood pressure, resulting in increased risk for CVD [22].

Several studies have demonstrated that overweight and obesity in childhood are risk factors for coronary disease and MetS in adulthood. In addition, hyperinsulinemia and hypertension are well-known risk factors for coronary heart disease. Our results show that these risk factors are present in a significant number of Syrian adolescents, mainly in those who are obese. Our data showed that overweight and obesity were associated with increased values in the components of MetS. These results are in agreement with the data of other studies investigating a similar association between the components of MetS and obesity [23-27].

Anthropometric measurements are crucial for MetS diagnosis. In addition, measurements of serum lipid fractions, fasting glucose values, and blood pressure in overweight and obese individuals are also important [28].

Table 3 Metabolic risk factors in the Syrian adolescents by body mass index category

\begin{tabular}{|c|c|c|c|c|c|}
\hline Characteristics & $\begin{array}{l}\text { Underweight } \\
\mathrm{BMI}<20\end{array}$ & $\begin{array}{l}\text { Normal } \\
20<\mathrm{BMI}<25\end{array}$ & $\begin{array}{l}\text { Overweight } \\
25<\mathrm{BMl}<30\end{array}$ & $\begin{array}{l}\text { Obesity } \\
\text { BMI >30 }\end{array}$ & LSD 5\% \\
\hline SBP (mmHg) & $121.85 \pm 16.60^{a}$ & $122.9 \pm 14.65^{a}$ & $124.2 \pm 13.2^{a}$ & $127.3 \pm 14.55^{b}$ & 14.55 \\
\hline $\mathrm{DBP}(\mathrm{mmHg})$ & $72.8 \pm 11.2^{\mathrm{a}}$ & $73.7 \pm 10.6^{a}$ & $76.4 \pm 10.2^{\mathrm{bc}}$ & $77.7 \pm 11.5^{c}$ & 10.72 \\
\hline $\mathrm{FBS}(\mathrm{mg} / 100 \mathrm{ml})$ & $90.5 \pm 10.5^{\mathrm{ab}}$ & $89.1 \pm 8.4^{\mathrm{a}}$ & $89.1 \pm 8.4^{\mathrm{ab}}$ & $91.6 \pm 7.9^{b}$ & 8.53 \\
\hline TG (mg/100 ml) & $89.5 \pm 51.5^{a}$ & $86.9 \pm 39.4^{a}$ & $99.8 \pm 44.6^{\mathrm{b}}$ & $125.1 \pm 62.9^{c}$ & 44.06 \\
\hline Chol (mg/100 ml) & $132.7 \pm 29.6^{\mathrm{a}}$ & $134.4 \pm 32.1^{\mathrm{a}}$ & $139.0 \pm 35.2^{b}$ & $153.6 \pm 34.6^{c}$ & 33.04 \\
\hline HDL-Chol (mg/100 ml) & $57.4 \pm 5.4^{\mathrm{ab}}$ & $57.0 \pm 5.7^{\mathrm{a}}$ & $57.7 \pm 5.6^{\mathrm{b}}$ & $56.8 \pm 5.5^{\mathrm{ab}}$ & 5.63 \\
\hline LDL-Chol (mg/100 ml) & $58.9 \pm 27.2^{\mathrm{a}}$ & $61.3 \pm 28.8^{\mathrm{a}}$ & $62.2 \pm 30.9^{\mathrm{a}}$ & $71.9 \pm 30.7^{b}$ & 29.34 \\
\hline TG/HDL-Chol & $1.56 \pm 0.91^{\mathrm{a}}$ & $1.53 \pm 0.70^{a}$ & $1.74 \pm 0.78^{b}$ & $2.22 \pm 1.15^{\mathrm{c}}$ & 0.78 \\
\hline
\end{tabular}

$B M I$ body mass index, LSD least significant difference, SBP systolic blood pressure, DBP diastolic blood pressure, FBS fasting blood sugar, $T G$ triglycerides, Chol cholesterol, HDL-Chol high-density lipoprotein cholesterol, LDL-Chol low-density lipoprotein cholesterol, TG/HDL-Chol triglycerides/ high-density lipoprotein cholesterol $\mathrm{a}, \mathrm{b}, \mathrm{c}$ mean values in the same row not sharing a superscript are significantly different 
Table 4 Sensitivity, specificity and area under curve of cut-off value of body mass index indicator in prediction of MetS for Syrian adolescents (18 to 19 years)

\begin{tabular}{|c|c|c|c|c|c|c|}
\hline Characteristics & Criteria & BMI cut-off value & Sensitivity \% & Specificity \% & Area under the curve & $P$ value \\
\hline $\mathrm{SBP}(\mathrm{mmHg})$ & $>135 \mathrm{mmHg}$ & 22.85 & 44.9 & 58.6 & 0.52 & 0.246 \\
\hline $\mathrm{DBP}(\mathrm{mmHg})$ & $>89 \mathrm{mmHg}$ & 23.45 & 49.6 & 66.5 & 0.59 & 0.000 \\
\hline FBS (mg/100 ml) & $>89 \mathrm{mg} / 100 \mathrm{ml}$ & 23.55 & 37.5 & 65.2 & 0.44 & 0.297 \\
\hline TG (mg/100 ml) & $>200 \mathrm{mg} / 100 \mathrm{ml}$ & 23.25 & 67.2 & 62.8 & 0.67 & 0.000 \\
\hline Chol (mg/100 ml) & $>200 \mathrm{mg} / 100 \mathrm{ml}$ & 23.75 & 61.3 & 68.2 & 0.67 & 0.000 \\
\hline HDL-Chol (mg/100 ml) & $<75 \mathrm{mg} / 100 \mathrm{ml}$ & 26.05 & 30.0 & 81.3 & 0.38 & 0.200 \\
\hline LDL-Chol (mg/100 ml) & $<155 \mathrm{mg} / 100 \mathrm{ml}$ & 24.35 & 60.0 & 71.9 & 0.69 & 0.037 \\
\hline TG/HDL-Chol & $>3 \mathrm{mg} / 100 \mathrm{ml}$ & 23.45 & 62.3 & 66.0 & 0.66 & 0.000 \\
\hline
\end{tabular}

$B M I$ body mass index, SBP systolic blood pressure, DBP diastolic blood pressure, FBS fasting blood sugar, TG triglycerides, Chol cholesterol, HDL-Chol high-density lipoprotein cholesterol, $L D L$-Chol low-density lipoprotein cholesterol, TG/HDL-Chol triglycerides/ high-density lipoprotein cholesterol

In this study, BMI was used to screen for the presence of MetS. Other studies concluded that BMI can predict the presence of multiple metabolic risk factors [29]. However, some studies found that a high body fat percentage was associated with increased cardiovascular risk regardless of BMI whose categorization resulted in an underestimation of the number of participants with cardiovascular risk factors [30, 31].

CVD is the most common cause of death in the world. The identification of individuals at increased CVD risk represents a priority [32]. Among the metabolic components, mean SBP $(123.4 \pm 14.55)$ was elevated in $19 \%$ of the whole group. Also, mean DBP $(74.4 \pm 10.72)$ was elevated in $12.7 \%$. Increased FBS, TG, Chol, and TG/ HDL-Chol were present in $1.2 \%, 2.8 \%, 3.6 \%$, and $5.5 \%$ of those investigated. Data from the present study suggested that populations who have high BMI, high SBP and DBP, and high levels of serum FBS, TG, Chol, LDLChol, and TG/HDL-Chol are more likely to experience a cardiovascular effect. In fact, LDL-Chol, which is closely related to CVD and mortality, remains the cornerstone of lipid management [33]. Epidemiological and clinical studies have consistently demonstrated that increased LDL-Chol is a major atherogenic lipoprotein for developing CVD and is currently recommended as the primary target for lipid-lowering therapy for the prevention and treatment of CVD [32, 34]. In some other studies, a significant relationship was found between cardiorespiratory fitness, BMI, and LDL-Chol [35]. Epidemiological investigations revealed that the occurrence of CVD in the obese population was 2.0 to 2.5 times that in people with a normal BMI [36]. The risk of hypertension is up to five times higher among obese people in comparison to normal weight individuals, and cross-sectional population surveys suggest that more than $85 \%$ of hypertension arises in individuals with BMI values above $25 \mathrm{~kg} / \mathrm{m}^{2}$ [24]. Our findings were in line with reports from many previous studies; Chen et al. [25], Mokdad et al. [26], and Wilson et al. [27] demonstrated that an increased risk of obesity-related morbidities was accompanied by an increase in BMI. Among the indicators used to predict the presence of MetS, TG, Chol, LDL-Chol, and TG/HDLChol showed a large area under the ROC curve, but LDLChol was the index that showed the greatest area under the ROC curve, which was similar to other studies $[3,32]$. Based on the sensitivity, specificity, and ROC calculation, we found that BMI had a good accuracy for identifying adolescents with some metabolic risk factors including DBP, TG, Chol, LDL-Chol, and TG/HDL-Chol; these data suggest the best BMI cut-offs ranged between 23.25 and $24.35 \mathrm{~kg} / \mathrm{m}^{2}$. Our cut-off values of BMI were lower than the current definitions of overweight (BMI >25) recommended by WHO $[1,13]$. These figures are in agreement with data from Asian populations [6], but lower than Western populations in USA and Europe [5]. On the other hand, our findings differ from those found in the Iraqi population (in men) [37]; they found that the best BMI cut-offs ranged between 24.9 and 25.4.

However, many studies have shown that CVDs occur more frequently at lower BMI in Asian than European populations, the mechanisms involved are yet to be demonstrated. Ethnic and racial differences in body composition and fat distribution have been studied. Although these studies have shown increasing BMI associated with larger increase in body fat content in Asians, growing evidence points to factors other than body fat content and fat distribution in determining higher prevalence of CVDs in these populations [38]. In a study on young adult Mauritians, the authors pointed out that the use of BMI cut-off values for classifying overweight and obesity should take into account both ethnicity and gender to avoid gross adiposity status misclassification in this population known to be at high risk for CVDs [39].

This study, however, brings an important epidemiological contribution to Syria, revealing important results, especially due to the lack of studies that evaluate the frequency of cardiovascular risk factors among Syrian adolescents and the value of BMI in predicting the components 
of MetS. Our findings support the notion of a relevant association between obesity at these early ages and the development of alterations in the components of MetS. Therefore, the planning and implementation of primary prevention programs by health care professionals to reduce potential cardiovascular risk factors is a priority. By such programs CVD risk factors can be reduced. Even small reductions in body weight are able to correct abnormalities in the components of MetS, such as hyperglycemia, hyperinsulinemia, and dyslipidemias. Interventions aimed at increasing physical activity and improving diet are cost effective for reducing the risk of diabetes and CVDs associated with obesity.

\section{Conclusions}

In conclusion, a strong association between overweight and obesity as determined by BMI and high concentrations of MetS components has been demonstrated in overweight and obese Syrian adolescents. BMI categories of $>23.45 \mathrm{~kg} /$ $\mathrm{m}^{2},>23.25 \mathrm{~kg} / \mathrm{m}^{2},>23.75 \mathrm{~kg} / \mathrm{m}^{2},>24.35 \mathrm{~kg} / \mathrm{m}^{2}$, and $>23.45 \mathrm{~kg} / \mathrm{m}^{2}$ were found to be positively associated with MetS components of DBP, TG, Chol, LDL-Chol, and TG/ HDL-Chol, respectively. These findings demonstrate the high risk of obesity at an early age through abnormal changes in MetS components.

\section{Acknowledgements}

The authors wish to express their deep appreciation to the Director General of AECS, Prof. I. Othman for his support and keen interest in the work.

\section{Funding}

This study was supported and funded by the International Atomic Energy Agency (IAEA) under the Technical Research Contract No. SYR/6/012. The fund was used to buy some required equipment and reagents.

\section{Availability of data and materials}

Please contact author for data requests.

\section{Authors' contributions}

Both authors (MALB and MAB) participated in the design of the study and performed the statistical analysis. MAB supervised the clinical and the laboratory work; MALB was the major contributor in writing the manuscript. The manuscript was read and approved by both authors.

\section{Competing interests}

The authors declare that they have no competing interests.

\section{Consent for publication \\ Not applicable.}

\section{Ethics approval and consent to participate}

The study protocol was approved by the scientific research and the ethical committee of the AECS, P.O. Box 6091, Damascus, Syria and also includes local institutional review board (IRB) approval. Each participant provided informed consent prior to participation after a detailed explanation of the study protocol. This study was performed in accordance with guidelines prescribed by the Declaration of Helsinki as developed by the World Medical Association.

\section{Publisher's Note}

Springer Nature remains neutral with regard to jurisdictional claims in published maps and institutional affiliations.

\section{Author details}

'Department of Radiation Technology, Atomic Energy Commission of Syria, P.O. Box 6091, Damascus, Syrian Arab Republic. ${ }^{2}$ Department of Nuclear Medicine, Atomic Energy Commission of Syria, P.O. Box 6091, Damascus, Syrian Arab Republic.

Received: 16 February 2017 Accepted: 3 May 2017

Published online: 25 June 2017

\section{References}

1. World Health Organization (WHO). Obesity and Overweight. Fact sheet No. 311. 2016. http://www.who.int/mediacentre/factsheets/fs311/en/. Accessed 15 May 2015.

2. Victora CG, Adair L, Fall C, et al. Maternal and child under nutrition: Consequences for adult health and human capital. Lancet. 2008;371:340-57.

3. Liu P, Ma F, Lou H, et al. The utility of fat mass index vs. body mass index and percentage of body fat in the screening of metabolic syndrome. BMC Public Health. 2013. doi:10.1186/1471-2458-13-629.

4. Asfaw A. The effects of obesity on doctor- diagnosed chronic diseases in Africa: empirical results from Senegal and South Africa. J Public Health Policy. 2008;27(3):250-64

5. Janssen I, Katzmarzyk PT, Ross R. Fitness alters the associations of BMI and waist circumference with total and abdominal fat. Obes Res. 2004;12:525-37.

6. Singh LCSP, Sikri SLCG, Garg LCMK. Body Mass Index and Obesity Tailoring "cut-off" for an Asian Indian Male Population. MJAFI. 2008;64(4):350-3.

7. Rastogi P, Pinto DS, Pai MR, et al. An autopsy study of coronary atherosclerosis and relation to anthropometric measurements/indices of overweight and obesity in men. J Forensic Legal Med. 2012;19:12-7.

8. Singh S, Virend K, Somers MD, et al. Physician diagnosis of overweight status predicts attempted and successful weight loss in patients with cardiovascular disease and central obesity. Am Heart J. 2010;160(5):934-42.

9. Calle EE, Thun M, Petrelli JM, et al. Body-mass index and mortality in a prospective cohort of U.S adults. N Engl J Med. 1999;34(15):1097-105.

10. Yancy Jr WS, Olsen MK, Westman EC, et al. Relationship between obesity and health- related quality of life in women. Obes Res. 2002; 10:1057-64

11. Evans B. Be fit not fat: Broadening the childhood obesity debate beyond dualisms. Children's Geographies. 2004;2(2):289-91.

12. Hadidy S, Bazerbashi MB, Tabbakh $\mathrm{H}$. The reference intervals of 12 serum biochemical analytes in normal Syrian population. Arab J Med. 1985;4:4-7.

13. Al-Bachir $\mathrm{M}$, Othman I. Validity of body mass index in determining prevalence of overweight and obesity among Syrian late adolescents boys. Soc Sci J. 2016:53:184-9.

14. Marotta T, Russo BF, Ferrara A. Triglyceride-to-HDL-cholesterol ratio and metabolic syndrome as contributors to cardiovascular risk in overweight patients. Obesity. 2010;18(8):1608-13.

15. Kesavachandran NC, Bihari B, Mathur N. The normal range of body mass index with high body fat percentage among male residents of Lucknow city in north India. Indian J Med Res. 2012;135:72-7.

16. Vanhala MJ, Vanhala PT, Keinanen-Kiukaanniemi SM, Kumpusalo EA, Takala JK. Relative weight gain and obesity as a child predicts metabolic syndrome as an adult. Int J Obes. 1999;23:656-9.

17. Reaven G. Insulin resistance, hypertension and coronary heart disease. J Clin Hypertens. 2003:5:269-74.

18. Ball GD, McCargar LJ. Childhood obesity in Canada: a review of prevalence estimates and risk factors for cardiovascular disease and type 2 diabetes. Can J Appl Physiol. 2003;28:117-40.

19. Goran MI, Ball GD, Cruz ML. Obesity and risk of type 2 diabetes and cardiovascular disease in children and adolescents. J Clin Endocrinol Metab. 2003;88:1417-27.

20. Li Cl, Kardia SL, Liu CS, et al. Metabolic syndrome is associated with change in sub-clinical healthy study. BMC Public Health. 2011. doi:10.1186/14712458-11-808.

21. Franco OH, Massaro JM, Civil J, et al. Trajectories of entering the metabolic syndrome: The Framingham Herat study. Circulation. 2009;120:1943-50.

22. Rizzo ACB, Goldberg TBL, Silvam CC, et al. Metabolic syndrome risk factors in overweight, obese, and extremely obese Brazilian adolescents. Nutr J. 2013;12:19-26.

23. Robinson LE, Daly CM, Wadsworth DD. Body mass index and blood pressure in rural, low socioeconomic children. Health. 2013;5:91-5. 
24. Palatini P, Coelotto G, Ragazzo F, et al. Phosducin rs12402521 polymorphism predicts development of hypertension in young subjects with overweight or obesity. Nutr Metab Cardiovasc Dis. 2011;23(4):323-9.

25. Chen G, Liu C, Yao J, et al. Overweight, obesity, and their associations with insulin resistance and B-cell function among Chinese: a cross-sectional study in China. Metab Clin Exp. 2010;59:1823-32.

26. Mokdad AH, Ford ES, Bowman BA, et al. Prevalence of obesity, diabetes, and obesity-related health risk factors. JAMA. 2003;289:76-89.

27. Wilson PW, D'Agnostino RB, Sullivan $L$, et al. Overweight and obesity as determinations of cardiovascular risk: the Framingham experience. Arch Intern Med. 2002;162:1867-72.

28. Walia R, Bhansali A, Ravikiran M, et al. High prevalence of cardiovascular risk factors in Asian Indians: A community survey - Chandigarh Urban Diabetes Study (CUDS). Indian J Med Res. 2014;139:252-9.

29. Liu Y, Tong G, Tong W, et al. Can body mass index, waist circumference, waist-hip ratio and waist-height ratio predict the presence of multiple metabolic risk factors in Chinese subjects? BMC Public Health. 2011;11:35.

30. Zeng Q, Dong SY, Sun XN, et al. Percent body fat is a better predictor of cardiovascular risk factors than body mass index. Braz J Med Biol Res. 2012;45:591-600.

31. Gomez- Ambrosi J, Silva C, Galofre JC, et al. Body mass index classification misses subjects with increased cardiometabolic risk factors related to elevated adiposity. Int J Obes. 2012;36:286-94.

32. Lu M, Lu Q, Zhang Y, et al. ApoB/apoA1 is an effective predictor of coronary heart disease risk in overweight and obesity. J Biomed Res. 2011;25(4):266-73.

33. Superko HR, Gadesam RR. Is it LDL particle size or number that correlates with risk for cardiovascular disease? Curr Atheroscler Rep. 2008;10:377-85.

34. Sharma RK, Singh VN, Reddy HK. Thinking beyond low-density lipoprotein cholesterol: strategies to further reduce cardiovascular risk. Vasc Health Risk Manag. 2009;5:793-9.

35. Bertolli A, Di-Daniele N, Cobelli M, et al. Lipid profile, BMl, body fat distribution and aerobic fitness in men with metabolic syndrome. Acta Diabetol. 2003:40 Suppl 1:S130-3.

36. Poirier P, Giles TD, Bray GA, et al. Obesity and cardiovascular disease: pathophysiology, evaluation, and effect of weight loss. Arterioscler Thromb Vasc Biol. 2006;26:968-76.

37. Mansour AA, A-Jazairi Ml. Cut-off values for anthropometric variable that confer increased risk of Typ 2 Diabetes mellitus and hypertension in Iraq. Arch Med Res. 2007:38:253-8.

38. Abate N, Chandalia M. Risk of obesity-related cardio metabolic complications in special populations: a crisis in Asians. Gastroenterology. 2017;152(7):1647-55.

39. Jones N, Dulloo AG. Body composition-derived cut-offs for overweight and obesity in Indians and Creoles of Mauritius: comparison with Caucasians. Int J Obes (Lond). 2016:40(12):1906-14.

\section{Submit your next manuscript to BioMed Central and we will help you at every step:}

- We accept pre-submission inquiries

- Our selector tool helps you to find the most relevant journal

- We provide round the clock customer support

- Convenient online submission

- Thorough peer review

- Inclusion in PubMed and all major indexing services

- Maximum visibility for your research

Submit your manuscript at www.biomedcentral.com/submit 